\title{
Análise da viabilidade econômica de uma Unidade de Beneficiamento de Sementes
}

Analysis of the economic viability of a Seed Processing Unit

\author{
Ana Paula Cunha1, Ricardo Harbs²*
}

\begin{abstract}
${ }^{1}$ Banco do Brasil - Especialista em Agronegócios - SCN, Quadra 2, Bloco A, Edifício Corporate Financial Center, $4^{\circ}$ andar, Sala 403, CEP 70712-900 - Brasília (DF), Brasil

2IPECEGE - Pesquisador Associado - Av. Alexandre Herculano, 120, sala T4 - Jardim Elite, CEP 13418445 - Piracicaba (SP), Brasil
\end{abstract}

\section{Resumo}

O objetivo deste trabalho consiste em apurar a viabilidade econômica de instalação de uma Unidade de Beneficiamento de Sementes - UBS, em uma propriedade rural localizada no município de Brasília/DF. Antes do projeto (cenário A), a soja produzida com qualidade para semente era entregue à uma grande empresa do setor, que se encarregava das etapas de beneficiamento e comercialização, remunerando o produtor com uma bonificação de $9 \%$ sobre o preço da soja. Em um segundo momento (cenário B), considera-se que o produtor investirá na construção de uma UBS em sua propriedade, realizando o beneficiamento da soja e sendo remunerado com uma bonificação de $40 \%$ sobre o preço do produto entregue à empresa. Conhecendo os resultados gerados em cada cenário, é possível verificar qual será a variação da receita líquida operacional, proporcionada pelo investimento, e calcular indicadores de viabilidade financeira como Valor Presente Líquido - VPL, Taxa Interna de Retorno - TIR, Payback descontado - PBD e Índice de Rentabilidade - IR. Além destes indicadores, calculados sob a hipótese de uso de recursos próprios, o trabalho contém uma análise sobre as condições de financiamento do projeto. Quando se considera a obtenção de crédito, que possui uma taxa de juros real negativa, observa-se que o VPL sofre um aumento significativo, passando de $R \$$ 11.082.279,19 (em caso de investimento com recursos próprios) para $R \$ 14.716 .511,27$.

Palavras-chave: processamento, sementes, soja

\begin{abstract}
The main objective of this study is to establish the economic viability of building a Seed Processing Unit - SPU, on a farm in the city of Brasilia/DF. Before the project (scenario A), the soybean produced with quality for seeds was delivered to a seeds company, which was in charge of the stages of processing and marketing, paying the farmer with a bonus of $9 \%$ on the price of soybeans. In a second step (scenario B), it is considered that the farmer will invest in building a SPU, making the processing of soybeans and being paid with a bonus of $40 \%$ on the price of the product delivered to the company. With results from both scenarios ( $A$ and $B)$, it is possible to estimate the change in the net operating revenue, provided by the investment, and calculate financial viability indicators such as Net Present Value - NPV, Internal Rate of Return - IRR, Payback discounted - PBD and the Profitability Index - PI. Along with these indicators - calculated without considering third parties capital - the work contains an analysis of the project financing conditions. When considering the loan, which has a negative real interest rate, it is observed that the NPV suffers a significant increase, from $R \$ 11,082,279.19$ (in case of investment with own resources) to $R \$ 14,716,511.27$.
\end{abstract}

Keywords: processing, seeds. soybean

\section{Introdução}

\footnotetext{
*Autor correspondente <ricardoharbs@pecege.com>

Enviado: 10 jun. 2015

Aprovado: 26 jul. 2015
} 
O sucesso da produção de soja depende, entre outros fatores, do estabelecimento de lavouras com adequadas populações de plantas, a fim de promover altos níveis de produtividade. França Neto e Kryzanowski (2000) destacam que a utilização de sementes de elevada qualidade em termos genéticos, físicos e sanitários, é o que assegura a obtenção dessa população adequada de plantas. O uso de sementes de soja com vigor inadequado pode fazer com que o produtor tenha que realizar o replantio da área, favorecendo uma menor rentabilidade do empreendimento em virtude da elevação dos custos e dos menores índices de produtividade.

Para a produção de sementes de soja, há necessidade do emprego de elevado nível tecnológico desde a fase de produção, armazenamento, processamento e transporte, além do controle de qualidade do produto, sendo totalmente justificável a participação, neste processo, de uma Unidade de Beneficiamento de Sementes - UBS. O beneficiamento de sementes consiste em todas as operações a que a semente é submetida, desde a recepção na UBS até a embalagem e distribuição, com o objetivo de aprimorar a sua qualidade (Carvalho; Nakagawa, 2000).

A UBS é uma estrutura que comporta máquinas que operacionalizam o processo de beneficiamento das sementes, contando com estruturas de armazenagem para a recepção dos grãos antes do beneficiamento (armazenamento por lotes e variedades) e garantindo, por conseguinte, a manutenção da qualidade fisiológica obtida após a colheita e na etapa final, depois que os produtos estão embalados e prontos para a comercialização. É preciso manter essas características até a semeadura em campo, o que evidencia a importância da armazenagem para a atividade de produção de sementes (Barros; Marcos Filho, 1997).

Após a colheita, a primeira etapa do processo corresponde ao transporte e recepção das sementes, que são descarregadas em uma moega e encaminhadas à linha de beneficiamento. Na sequência, as sementes de soja são submetidas ao processo de pré-limpeza, que consiste na remoção de impurezas grosseiras, através de um equipamento com sistema de ventilação e peneiras. Posteriormente, as sementes com grau de umidade superior a $12 \%$ são submetidas a um processo de secagem. Com a umidade reduzida a um nível seguro, as sementes passam por um novo processo de limpeza, mais rigoroso, que tem por objetivo remover todo o material indesejado (França Neto et al., 2007).

Após as etapas de secagem e limpeza, começam os procedimentos relativos à separação e classificação (por forma, tamanho, densidade e cor). A classificação por forma é realizada através de equipamentos em espiral, que separam as sementes 
arredondadas daquelas que possuem forma achatada. A produção ainda pode ser dividida em lotes menores, com maior uniformidade de tamanho. Para essa finalidade, são utilizados equipamentos como a "padronizadora de tamanho", que separa as sementes de acordo com largura e espessura, além de discos ou cilindros alveolados, que as separam de acordo com o comprimento (França Neto et al., 2007).

Nesse último processo, de separação por tamanho, sugere-se que as sementes sejam classificadas em intervalos de 0,5 milímetros. Na sequência, um equipamento denominado "mesa densimétrica" garante que as sementes mais leves sejam separadas das mais pesadas. E para concluir a etapa de classificação, sementes com características físicas similares, mas diferentes colorações, podem ser separadas por equipamentos eletrônicos. Por fim, as sementes limpas e classificadas ainda podem sofrer um tratamento com produtos químicos (fungicidas e/ou inseticidas), antes de serem enviadas às ensacadoras automáticas, onde são acondicionadas em embalagens de $40 \mathrm{~kg}$. Após o beneficiamento, a semente embalada poderá ser armazenada em silo convencional ou climatizado (França Neto et al., 2007).

Microrregiões que possuem, entre suas características geográficas, elevada altitude e baixa umidade relativa do ar, podem constituir uma boa alternativa para a produção e armazenagem de sementes (Dajoz, 1981; Costa et al., 1994; França Neto; Krzyzanowski, 2000). Nesse sentido, a região de Brasília/DF e entorno, como o município de Formosa/GO, possuem características adequadas à atividade. Essa é uma das razões pelas quais, na região, encontram-se grandes indústrias de sementes como Pionner, Syngenta, Sementes Produtiva, Sementes Quati, entre outras.

O estudo visando à instalação de uma UBS, em uma propriedade rural localizada em Brasília/DF, foi elaborado com base no caso de um empresário que produz grãos destinados a sementes. A área total de plantio chega a aproximados nove mil hectares, distribuídos nos municípios de Brasília/DF, Mimoso de Goiás/GO e Unaí/MG. O produtor em questão produziu, na safra 2012/2013, um total de 25.419 toneladas de grãos de soja, sendo que $65 \%$ da produção foi destinada ao beneficiamento de sementes. Do total, 11.592 toneladas de soja foram produzidas nas fazendas de Brasília, 4.055 toneladas foram produzidas nas fazendas de Unaí e 9.772 toneladas foram produzidas nas fazendas de Mimoso de Goiás/GO. Atualmente, o produtor participa apenas da etapa agrícola, que consiste na produção de soja em grãos com qualidade para beneficiamento de sementes, em parceria com uma grande empresa do setor. Essa parceria rende uma bonificação de $9 \%$ sobre o preço dos grãos fornecidos à empresa. 
O percentual de soja produzido com qualidade para beneficiamento depende da tecnologia e investimentos aplicados na fase de produção a campo. No caso do produtor, o rendimento das lavouras, no que diz respeito à qualidade dos grãos para beneficiamento, é de $65 \%$, o que representa 16.522 toneladas de grãos de soja, ou 413.059 sacas de semente de soja de $40 \mathrm{~kg}$. A produção remanescente, equivalente a 8.897 toneladas, é comercializada como soja em grão.

Com a construção da UBS, o produtor participará de mais uma fase do processo produtivo, agregando valor ao seu produto. A remuneração sobre a produção passará de $9 \%$ para $40 \%$ sobre o preço de toda a soja beneficiada, ensacada e armazenada como semente. A UBS deverá beneficiar toda a soja destinada à semente, produzida nos municípios de Unaí/MG, Mimoso de Goiás/GO e Brasília/DF. A produção de soja, em Brasília/DF, proporcionará 188.370 sacas de sementes; Mimoso de Goiás/GO contribuirá com 158.795 sacas e Unaí/MG participará com 65.894 sacas de sementes.

Nesta modalidade de parceria com a sementeira, o produtor terá o custo com a implantação da lavoura e sua condução, o frete com o deslocamento da safra de soja das regiões de Unaí/MG e Mimoso de Goiás/GO para Brasília/DF, bem como os custos que envolvem o beneficiamento de sementes: energia elétrica, mão-de-obra, embalagens, sacarias de papel multifoliado, palhetes, máquinas de impressão em embalagens, empilhadeira movida a gás, armazenagem, "big bags", amostragem, identificação, e manutenção de máquinas e equipamentos.

O produtor decidirá, a cada safra, quais variedades de soja e em quais proporções produzirá e beneficiará para cada empresa, de forma a descentralizar sua produção. Neste caso, salienta-se que o produtor não se caracteriza como prestador de serviço, uma vez que domina todas as etapas do processo produtivo, desde a implantação da lavoura até o ensaque da soja semente. A soja já beneficiada e ensacada ficará armazenada na estrutura do produtor, e as empresas realizarão a sua comercialização com carregamento dos caminhões na propriedade.

Como o objetivo principal do produtor, a princípio, é investir na etapa de beneficiamento dos grãos de soja, esta monografia se restringe a um estudo de viabilidade financeira para instalação de uma UBS na fazenda localizada em Brasília/DF. Pretende-se, portanto, testar a hipótese de que a instalação da UBS proporcionará um resultado que justifique a realização do projeto. Também é importante salientar que o estudo se restringe às atividades de produção e comercialização de soja em grão (beneficiada ou não), sendo que as outras culturas estão fora do escopo do trabalho e não serão consideradas na análise financeira. 


\section{Materiais e métodos}

Para atingir o objetivo proposto nesta monografia, de verificar a viabilidade financeira de implantação de uma UBS em Brasília/DF, foram elaborados fluxos de caixa correspondentes a dois cenários distintos, denominados $\mathrm{A}$ e $\mathrm{B}$. No cenário $\mathrm{A}$, o produtor não possui UBS e toda a soja com qualidade para beneficiamento é vendida para sementeiras, as quais bonificam o produtor em $9 \%$ sobre o preço da soja em grão (Anexo A). No cenário $B$, por outro lado, considerou-se a hipótese de que o produtor instalou uma UBS e beneficia toda a soja destinada à semente. Após o beneficiamento, o produto é vendido para sementeiras que, neste caso, bonificam o produtor em $40 \%$ sobre o preço da soja em grão (Anexo B). Salienta-se que o projeto de beneficiamento de sementes tem 20 anos de duração, sendo que o investimento ocorre no primeiro ano e, no último, a atividade é encerrada e os ativos fixos da UBS são liquidados pelo seu valor residual ( $20 \%$ do valor referente ao investimento inicial).

A diferença entre o Valor Presente Líquido - VPL obtido nos cenários A e B corresponde, precisamente, ao valor agregado pelo projeto de instalação da UBS. O valor agregado também pode ser mensurado através do fluxo de caixa incremental, no qual a diferença entre os fluxos dos projetos é calculada em todos os períodos (20 anos), e os valores são atualizados de acordo com a Taxa Mínima de Atratividade - TMA, que corresponde à remuneração que o capital receberia em sua melhor alternativa ao empreendimento (Anexo C). Se o fluxo de caixa incremental apresentar VPL positivo, infere-se que o investimento possui viabilidade financeira. Também é importante observar que, em ambos os cenários ( $\mathrm{A}$ e B), considerou-se apenas o uso de recursos próprios. Com o objetivo de mensurar o impacto do crédito subsidiado sobre o VPL do projeto, o fluxo de financiamento foi calculado separadamente.

A Tabela 1 contém a produção de sementes e de soja convencional, bem como a área total destinada ao cultivo de soja, de acordo com a localização das propriedades. 
Tabela 1. Produção (sementes e soja convencional) e área total destinada ao cultivo de soja, de acordo com a localização das propriedades

\begin{tabular}{lcccc}
\hline \multicolumn{1}{c}{ Município/UF } & Sementes & $\begin{array}{c}\text { Soja } \\
\text { convencional }\end{array}$ & Área \\
\hline & & $\mathrm{kg}$ & & ha \\
Brasília/DF & 7.534 .800 & & 4.057 .200 & 3.567 \\
Mimoso de Goiás/GO & 6.351 .800 & 3.420 .200 & 3.007 \\
Unaí/MG & 2.635 .750 & 1.419 .250 & 1.248 \\
Total & $\mathbf{1 6 . 5 2 2 . 3 5 0}$ & $\mathbf{8 . 8 9 6 . 6 5 0}$ & $\mathbf{7 . 8 2 1}$ \\
\hline
\end{tabular}

Fonte: Dados da pesquisa

Na composição dos fluxos de caixa dos cenários $A$ e $B$, foram utilizadas as séries históricas de preços e custos da lavoura de soja entre as safras 2009/10 e 2013/14, obtidas por meio de entrevistas a produtores da região e ao produtor em questão, além do uso da base de dados de uma instituição financeira. Os custos e a série histórica de preços da lavoura de soja foram deflacionados pelo Índice Geral de Preços - IGP-DI, da Fundação Getúlio Vargas, com base em dezembro de 2013. Em seguida, os preços de soja foram estipulados, em cada localidade, de acordo com a média dos valores registrados durante o período de comercialização do produtor, entre os meses de maio e setembro. A Tabela 2 contém a média de preços e os custos operacionais de produção de soja, por localidade.

Tabela 2. Preço médio da soja convencional, em reais por saca de $60 \mathrm{Kg}$ ( $\mathrm{R} \$ /$ saca) e custo operacional de produção da soja, em reais por hectare $(\mathrm{R} \$ / \mathrm{ha})$, segundo localidades (safras 2009/10 - 2013/14)

\begin{tabular}{lcc}
\hline \multicolumn{1}{c}{ Município / UF } & $\begin{array}{c}\text { Preço da soja } \\
\text { convencional }\end{array}$ & $\begin{array}{c}\text { Custo operacional de } \\
\text { produção da soja }\end{array}$ \\
\hline & $\mathrm{R} \$ /$ saca & $\mathrm{R} \$ /$ ha \\
Brasília/DF & 53,59 & $1.372,35$ \\
Mimoso de Goiás/GO & 53,59 & $1.372,35$ \\
Unaí/MG & 56,18 & $1.394,21$
\end{tabular}

Fonte: Dados da pesquisa

(1) Valores deflacionados, pelo Índice Geral de Preços - IGP-DI, da Fundação Getúlio Vargas, com base em dezembro de 2013

Os custos considerados no cenário $\mathrm{B}$, referentes ao frete da soja produzida em Mimoso de Goiás/GO e Unaí/MG, e transportada para UBS em Brasília/DF, são de $R \$$ 
30,00/t e $R \$ 35,00 / t$, respectivamente. Cumpre observar que estes custos foram obtidos com o agrônomo do produtor rural.

Os custos operacionais da UBS foram obtidos com um produtor rural que já está inserido na atividade de beneficiamento de sementes. Dentre os custos estimados com o beneficiamento dos grãos, verifica-se que o mais representativo é o custo com a certificação, seguido do custo com sacaria e a mão de obra (Tabela 3).

Tabela 3. Custos fixos da Unidade de Beneficiamento de Sementes - UBS

\begin{tabular}{lcc}
\hline Item & Custo fixo anual & Participação \\
\hline & $\mathrm{R} \$$ & $\%$ \\
Certificação & $826.118,00$ & 70,9 \\
Mão de obra & $214.790,68$ & 18,4 \\
Análises & $123.917,70$ & 10,6 \\
Total & $\mathbf{1 . 1 6 4 . 8 2 6 , 3 8}$ & $\mathbf{1 0 0 , 0}$ \\
\hline
\end{tabular}

Fonte: Dados da pesquisa

Quanto aos custos variáveis de beneficiamento, a Tabela 4 permite verificar que o custo da sacaria possui a maior participação, respondendo por mais de $60 \%$ do total. A mão de obra variável aparece em segundo lugar, com uma participação de $36,5 \%$ do custo variável total, em reais por saca de $40 \mathrm{~kg}$.

Tabela 4. Custos variáveis com o beneficiamento de sementes, em reais por saca de 40 $\mathrm{kg}(\mathrm{R} \$ /$ saca $)$

\begin{tabular}{lcc}
\hline Item & $\begin{array}{c}\text { Custo } \\
\text { variável }\end{array}$ & $\begin{array}{c}\text { Part. } \\
(\%)\end{array}$ \\
\hline Sacaria $(\mathrm{R} \$ /$ saca) & 1,58 & $60,1 \%$ \\
Mão de obra $(\mathrm{R} \$ /$ saca) & 0,96 & $36,5 \%$ \\
Energia $(\mathrm{R} \$$ saca) & 0,09 & $3,4 \%$ \\
Total $(\mathbf{R} \$$ /saca) & $\mathbf{2 , 6 3}$ & $\mathbf{1 0 0 , 0 \%}$ \\
\hline
\end{tabular}

Fonte: Dados da pesquisa

Os tributos recolhidos, nos cenários $\mathrm{A}$ e $\mathrm{B}$, foram calculados com base nas regras apresentadas por Bacha (2014), conforme indicado a seguir:

- Imposto de Renda Pessoa Física - IRPF: considerou-se o lucro presumido de $20 \%$ sobre o faturamento e, em seguida, aplicou-se uma taxa de $27,5 \%$ sobre este valor, 
subtraindo $R \$ 9.913,83$, que corresponde ao desconto definido pela Receita Federal para o ano de 2014;

- Fundo de Assistência ao Trabalhador Rural - FUNRURAL: 2,3\% sobre o faturamento; - Imposto sobre Circulação de Mercadorias e Serviços - ICMS sobre o frete da soja: 7\% sobre o frete da soja produzida em Minas Gerais e Goiás, e enviada para processamento no Distrito Federal;

- ICMS de venda da soja: 7\% sobre o preço da soja produzida em Minas Gerais e Goiás, e enviada para processamento no Distrito Federal;

- ICMS de venda da soja beneficiada para sementeiras: 7\% sobre o preço da soja (de forma não cumulativa), com bonificação de $40 \%$.

Os coeficientes técnicos, custos operacionais, preços e tributos supracitados foram empregados nos fluxos de caixa dos cenários $A$ e $B$, os quais tiveram seus resultados comparados com o objetivo de verificar qual seria o incremento, em termos de receita líquida operacional, proporcionado pelo investimento em uma UBS. Posteriormente, para inferir sobre a viabilidade de realizar o projeto com recursos próprios, foram calculados os seguintes indicadores: VPL, TIR, Payback Descontado e IR. As fórmulas de cálculo destes indicadores, largamente utilizados no âmbito da avaliação de projetos, são apresentadas a seguir:

Valor Presente Líquido - VPL: o VPL constitui a ferramenta mais adequada para avaliar o mérito de um projeto de investimento. A superioridade do VPL em relação aos demais indicadores de viabilidade deve-se, em primeiro lugar, ao fato de que esse método considera o valor do dinheiro no tempo, permitindo a atualização monetária do balanço entre receitas e custos de cada período, ao longo de toda a vida útil do empreendimento. Em segundo lugar, é importante observar que o VPL também leva em conta o custo de oportunidade do capital, representado pela taxa de desconto (r), que corresponde à remuneração que este receberia em sua melhor alternativa ao projeto (Buarque, 1991; Ross et al., 2002). Conforme indicado pela equação 1, o VPL pode ser calculado pela soma algébrica dos fluxos de caixa atualizados através da taxa de desconto.

$$
\mathrm{VPL}=\mathrm{I}_{0}+\sum_{\mathrm{t}=0}^{\mathrm{T}} \frac{\mathrm{RLO}_{\mathrm{t}}}{(1+\mathrm{r})^{\mathrm{t}}}
$$

Onde, Io: investimento inicial; T: duração do projeto; RLO: Receita Líquida Operacional; $r$ : taxa de desconto 
Segundo Buarque (1991), a obtenção de um VPL maior do que zero indica que o projeto de investimento tem mérito positivo. E ao realizar um estudo comparativo entre projetos alternativos, deve-se optar por aquele que apresentar o maior VPL.

Taxa Interna de Retorno - TIR: a TIR corresponde à taxa de desconto que torna o VPL do projeto nulo. Alternativamente, pode-se dizer que a TIR é a taxa de desconto que faz com que o valor presente do fluxo de custos seja igual ao valor presente do fluxo de benefícios do projeto (Buarque, 1991). Dessa forma, se (eq. 2):

$$
\mathrm{VPL}=\mathrm{I}_{0}+\sum_{\mathrm{t}=0}^{\mathrm{T}} \frac{\mathrm{RLO}_{\mathrm{t}}}{(1+\mathrm{r} *)^{\mathrm{t}}}=0
$$

Então, $r^{*}$ é a TIR do projeto.

A obtenção de uma TIR igual ou maior do que o custo de oportunidade do capital, dado pela taxa de desconto, indica a viabilidade do projeto. E quanto maior for a TIR, maior será a atratividade do investimento (Contador, 2008).

Payback Descontado - PBD: o PBD equivale ao número de períodos necessários para que os fluxos de caixa descontados se igualem ao investimento inicial. Segundo Contador (2008), o PBD possui deficiências que impedem a sua utilização como critério exclusivo na definição do mérito de um projeto. Apesar de considerar o valor do dinheiro no tempo, o indicador ignora todos os fluxos previstos após o período de recuperação do investimento. Devido a essa característica, o PBD é particularmente ineficiente nos casos de projetos não convencionais, nos quais existe a necessidade de recomposição dos investimentos.

O PBD pode ser definido através das equações (2) e (3):

$$
\operatorname{PBD}=\alpha
$$

Tal que:

$$
I_{\mathrm{o}}+\sum_{\mathrm{t}=0}^{\alpha} \frac{\mathrm{RLO}_{\mathrm{t}}}{(1+\mathrm{r})^{\mathrm{t}}} \geq 0 \text { e } I_{\mathrm{o}}+\sum_{\mathrm{i}=0}^{\alpha-1} \frac{\mathrm{C}_{\mathrm{t}}}{(1+\mathrm{r})^{\mathrm{t}}}<0
$$

Conforme indicado pela equação 4, o coeficiente $\alpha$ indica o período em que ocorre a reversão de sinal do somatório dos fluxos de caixa descontados. Apesar de fornecer uma informação relevante, o PBD é um indicador auxiliar, que deve ser encarado como um complemento à análise de projetos (Contador, 2008). 
Índice de Rentabilidade - IR: o IR corresponde à razão entre o valor presente dos fluxos de caixa posteriores ao investimento inicial e o valor presente dos fluxos de caixa relativos a esse investimento (Contador, 2008). Nesse sentido, a obtenção de um Índice de Rentabilidade maior do que a unidade (IR $>1$ ) indica que o projeto possui VPL positivo. No caso de um projeto independente, esse resultado é suficiente para que se recomende a sua aceitação (Ross et al., 2007) (eq. 5)

$$
I R=\frac{\sum_{t=0}^{T} \frac{R L O_{t}}{(1+r)^{t}}}{I_{0}}
$$

Nos projetos A e B, analisados com o objetivo de inferir sobre o valor agregado pela atividade de beneficiamento de sementes, a Taxa Mínima de Atratividade - TMA foi definida de acordo com a média da taxa de juros real observada entre janeiro de 2009 e dezembro de 2013. Mais especificamente, a taxa de juros real foi calculada de acordo com a equação 6, apresentada em Mankiw (2000):

$$
r=\frac{(1+i)}{(1+\pi)}-1
$$

Onde, r: taxa real de juros; i: taxa nominal de juros; m: taxa de inflação.

A média anual da taxa Over/SELIC, observada entre janeiro de 2009 e dezembro de 2013, foi empregada como taxa nominal de juros - i. A taxa de inflação - $\pi$, por outro lado, foi estipulada de acordo com a média anual do Índice Nacional de Preços ao Consumidor Amplo - IPCA.

\section{Resultados e Discussão}

Para inferir sobre a viabilidade econômica do investimento visando a instalação de uma UBS, foi necessário estabelecer um comparativo entre dois cenários distintos $(A$ e $B)$. No primeiro caso (cenário $A$ ), elaborou-se um fluxo de caixa para representar a situação ex ante do produtor rural, que não possuía UBS e auferia uma bonificação de 9\% sobre o preço dos grãos de soja fornecidos à empresa de sementes. Alternativamente, considerou-se uma situação hipotética em que o produtor rural utilizaria recursos próprios para instalar uma UBS em sua propriedade, auferindo um bônus de $40 \%$ sobre o preço da soja beneficiada (cenário B). 
A construção dos fluxos de caixa permitiu verificar que o investimento em uma UBS teria, como contrapartida, um incremento de $R \$ 1.464 .406,69$ na receita líquida anual do empreendimento, ao longo de 19 anos (Anexo C). No último período, em que ocorre o encerramento da atividade de beneficiamento, a variação da receita líquida operacional seria atribuída, exclusivamente, a liquidação do ativo residual, constituído de máquinas e equipamentos usados que seriam vendidos por $\mathrm{R} \$ 1.901 .922,29$ (20\% do valor referente ao investimento inicial) (Figura 1).

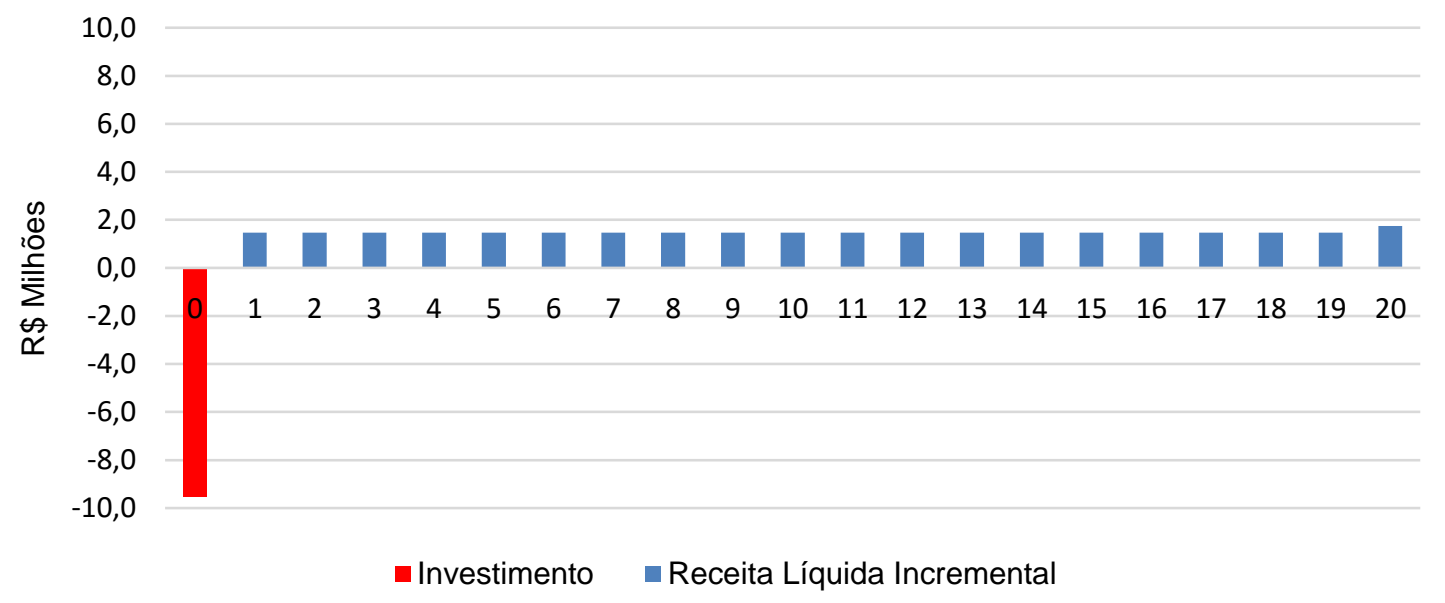

Figura 1. Fluxo de caixa incremental: capital próprio

Fonte: Resultados da pesquisa

Considerando uma TMA (real) de 3,7\% a.a., observa-se que o projeto de instalação da UBS com recursos próprios, em uma propriedade rural localizada no município de Brasília/DF, apresenta viabilidade financeira. O VPL do fluxo de caixa incremental, que constitui o benefício líquido proporcionado pelo investimento, seria de $\mathrm{R} \$$ 11.082.279,19. Os outros indicadores de viabilidade (TIR, PBD e IR), corroboram com este resultado (Tabela 4).

Tabela 4. Indicadores de viabilidade financeira - instalação de UBS com capital próprio

\begin{tabular}{lc}
\hline Indicadores & Resultado \\
\hline VPL $(\mathrm{R} \$)$ & $11.082 .279,19$ \\
TIR $(\%)$ & 14,4 \\
PBD (anos) & 8,6 \\
IR & 2,17 \\
\hline
\end{tabular}

Fonte: Resultados da pesquisa 
As condições de financiamento da UBS, por meio da linha de crédito do Programa de Construção e Ampliação de Armazéns - PCA, correspondem a um prazo de 15 anos de pagamento, com três anos de carência e taxa de juros nominal de 4\% a.a. Também é importante mencionar que a linha de crédito do PCA permite o financiamento de $100 \%$ do valor referente ao investimento para instalação da UBS, que corresponde a $\mathrm{R} \$ 9.509 .611,46$ (Figura 2).

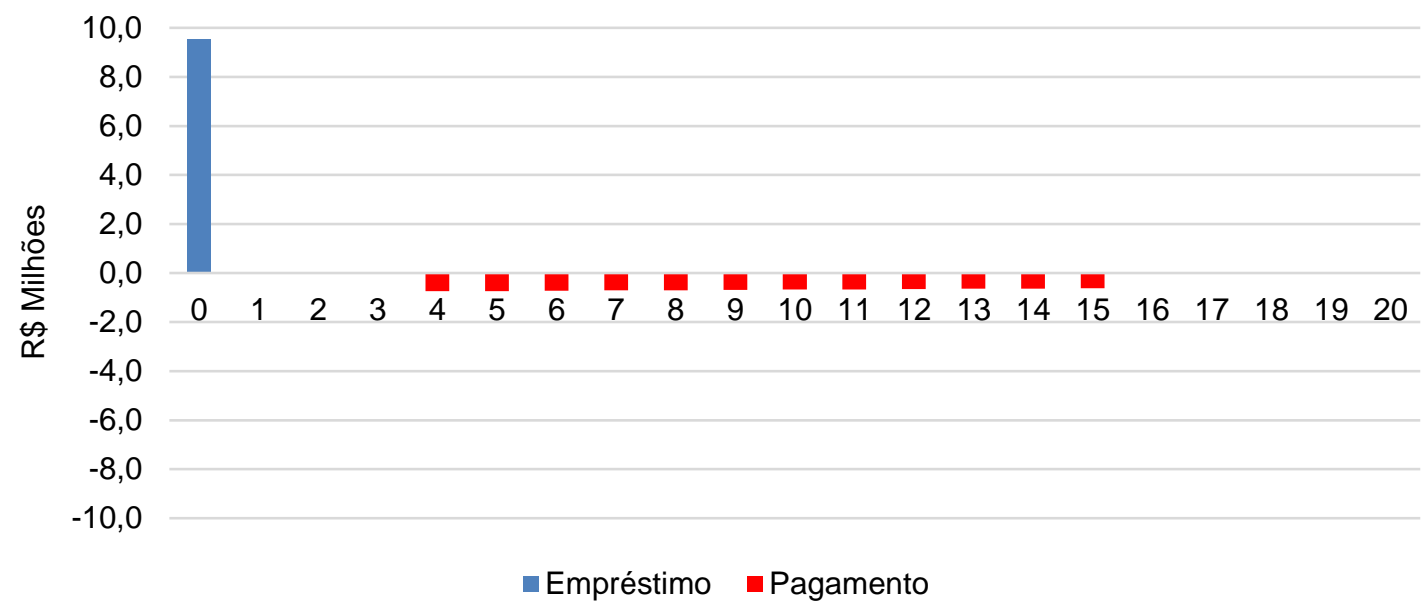

Figura 2. Fluxo do financiamento da UBS

Fonte: Resultados da pesquisa

Apurando o IPCA médio anual, verificou-se que a taxa de juros anual do financiamento é negativa, da ordem de $-1,6 \%$ a.a., o que contribui positivamente para com o resultado final de implantação do projeto. O VPL do fluxo do financiamento, no qual se evidencia o impacto positivo do crédito subsidiado, seria de $R \$ 3.634 .232,08$, representando $24,8 \%$ do benefício líquido proporcionado pelo investimento (Anexo D). Dessa forma, o VPL total do projeto, dado pela soma entre o fluxo de caixa incremental e o fluxo de financiamento, corresponde a $R \$ 14.716 .511,27$ (Tabela 5).

Tabela 5. Composição do VPL - instalação de UBS com capital de terceiros

\begin{tabular}{lcc}
\hline Descrição & VPL & Participação \\
\hline & $\mathrm{R} \$$ & $\%$ \\
Fluxo de caixa incremental & $11.082 .279,19$ & 75,3 \\
Fluxo de financiamento & $3.634 .232,08$ & 24,7 \\
Total & $14.716 .511,27$ & 100,0 \\
\hline Fonte: Resultados da pesquisa & &
\end{tabular}


Apesar destes resultados, não se pode perder de vista que a análise foi realizada com base em parâmetros (preços, produtividades e custos médios) observados entre as safras $2009 / 10$ e $2013 / 14$. Mesmo que todos os cálculos apontem para a viabilidade do projeto, ainda restam dúvidas quanto ao seu desempenho diante do risco e de eventuais mudanças conjunturais. Portanto, um estudo mais rigoroso requer que aspectos inerentes ao risco (climático, de mercado, entre outros), sejam incorporados à avaliação financeira do projeto.

Nesse sentido, a análise de sensibilidade é uma ferramenta que pode ampliar a compreensão sobre a susceptibilidade dos resultados em relação a oscilações de variáveis que possuem reconhecida importância no âmbito de um modelo. Para realizar esse tipo de análise, é necessário induzir uma variação em determinada variável, mantendo-se todos os outros parâmetros inalterados, e registrar os indicadores de viabilidade financeira obtidos após a alteração. O procedimento deve ser repetido para todas as variáveis selecionadas (Thal, 1982). Neste trabalho, a análise de sensibilidade foi empregada para variáveis como produtividade e preço da soja, além da taxa de juros real do financiamento bancário.

No caso da produtividade da soja, a análise de sensibilidade revelou que, independentemente do recurso utilizado (próprio ou de terceiros), um aumento de 10 $\mathrm{kg} / \mathrm{ha}$ tem, como consequência, um acréscimo de $\mathrm{R} \$ 60.748,00$ no VPL do empreendimento. A Figura 3 ilustra a relação entre VPL e produtividade da soja, de acordo com o tipo de recurso utilizado.

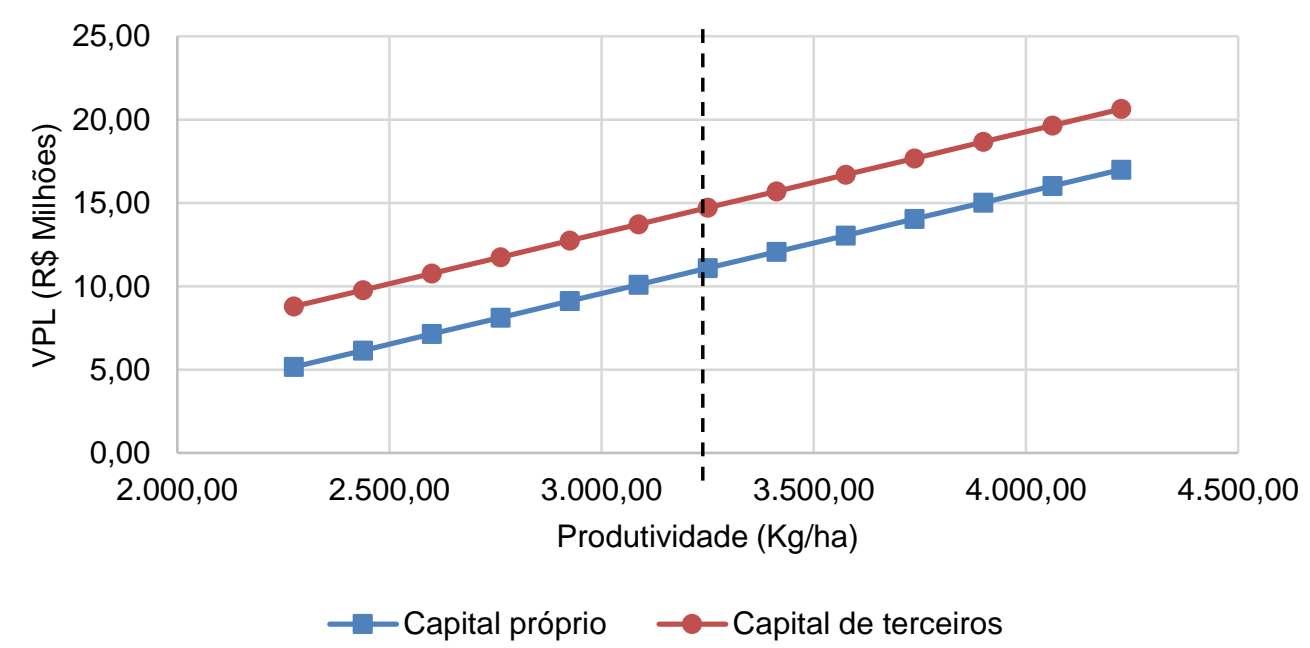

Figura 3. Relação entre produtividade da soja e VPL da UBS, por tipo de recurso (próprio ou de terceiros)

Fonte: Resultados da pesquisa 
O preço da soja corresponde a uma variável de grande relevância para o projeto, dependendo de fatores tão diversos como o clima em outras regiões produtoras, estoques internacionais, câmbio e perspectivas para a safra norte-americana. Como o produtor rural, por maior que seja, não possui qualquer influência sobre estas variáveis, é muito importante conhecer o patamar de preço a partir do qual a UBS deixa de ser viável.

Na Figura 4, que ilustra a relação entre preço da soja e VPL da UBS, observase que o investimento visando a instalação de uma UBS deixa de ser viável a partir de $R \$ 42,68$ e $R \$ 39,11$ para projetos com recursos próprios e de terceiros, respectivamente. Nesse caso, a análise de sensibilidade também revelou que, independentemente do recurso utilizado (próprio ou de terceiros), um aumento de 1,00 $R \$ /$ saca tem, como consequência, um acréscimo de $R \$ 1.015,809,00$ no VPL do empreendimento.

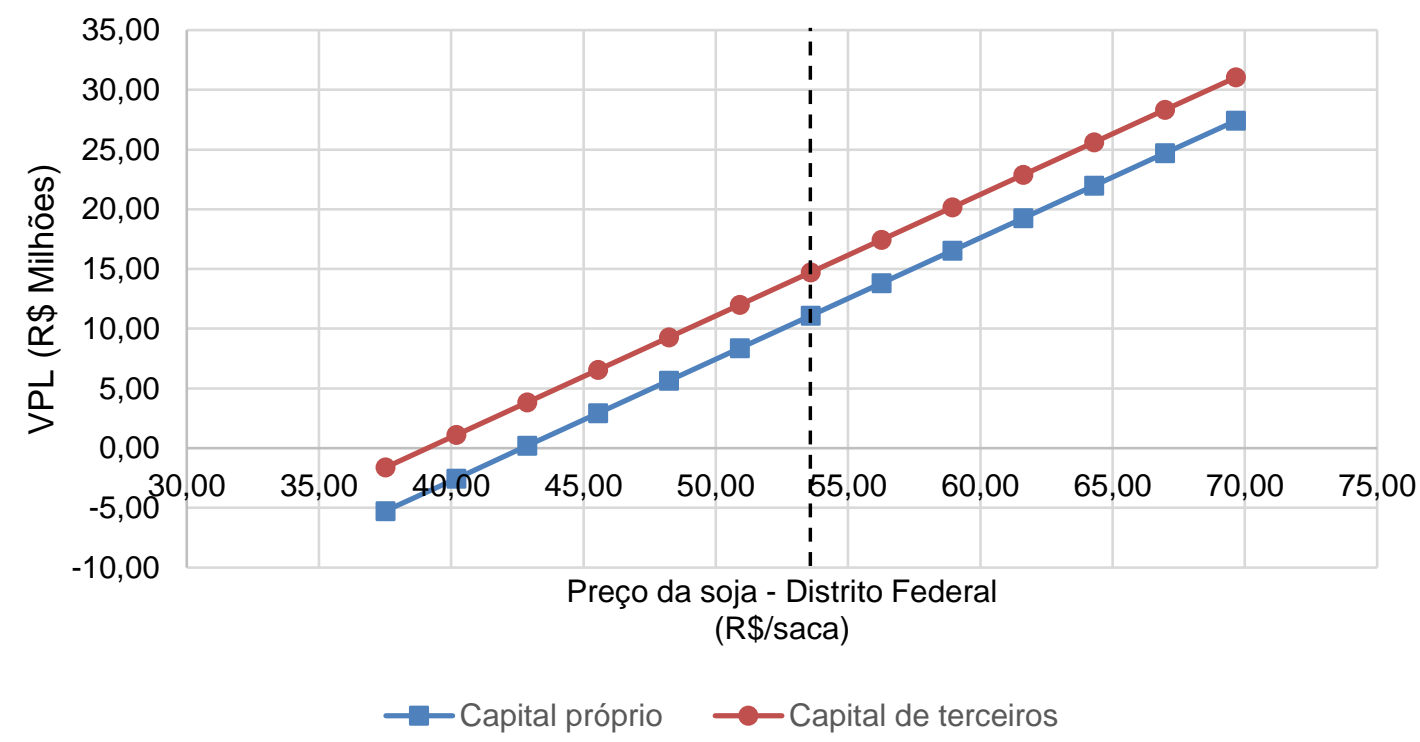

Figura 4. Relação entre preço da soja e VPL da UBS, por tipo de recurso (próprio ou de terceiros)

Fonte: Resultados da pesquisa

Conforme visto anteriormente, as condições de financiamento tem um grande impacto sobre o resultado de um projeto realizado com recursos de terceiros. Especial atenção deve ser reservada à taxa de juros real, que depende da expectativa de inflação, bem como da taxa de juros nominal estipulada pela instituição financeira. Como estas variáveis podem sofrer, de um ano para outro, significativas alterações, julgou-se 
que seria relevante estabelecer uma relação entre a taxa de juros real, que é a variável que efetivamente interessa ao investidor, e o VPL da UBS (Figura 5).

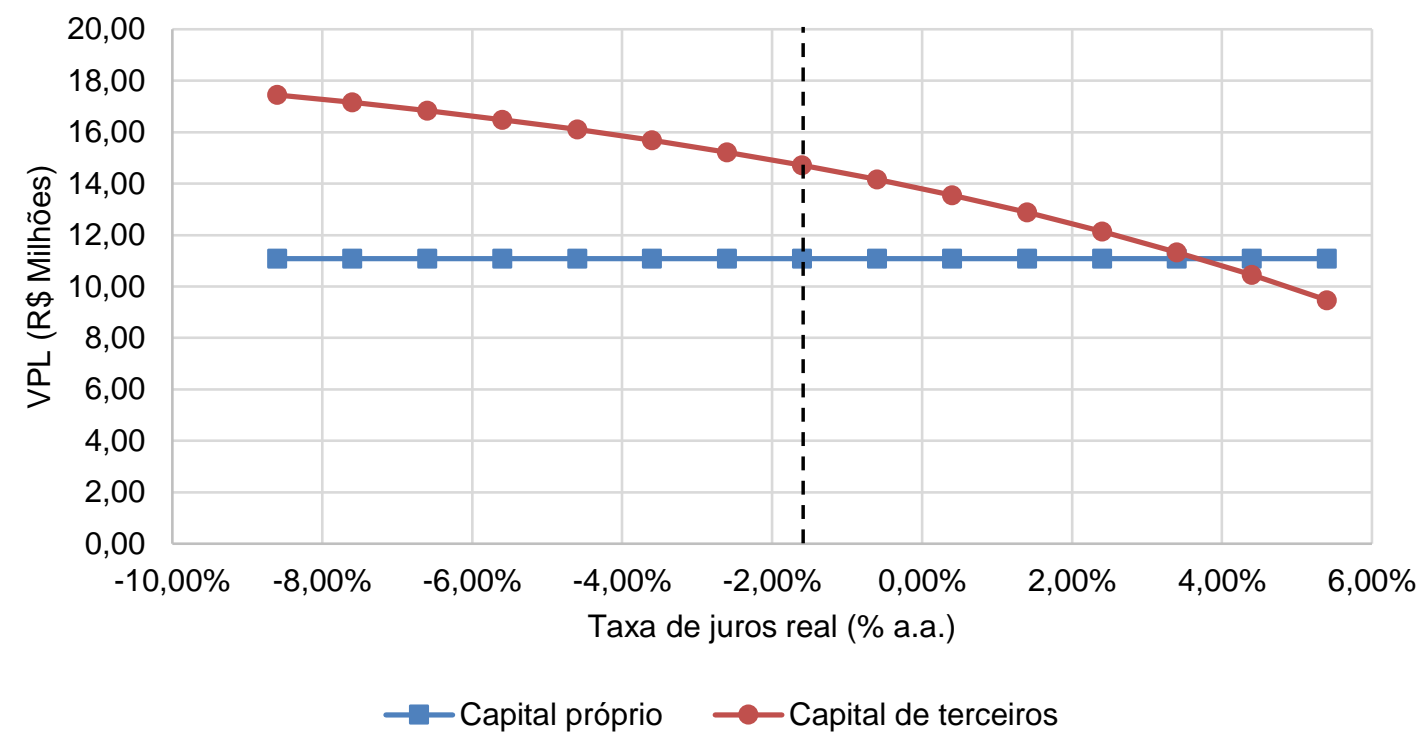

Figura 5. Relação entre taxa de juros real e VPL da UBS, por tipo de recurso (próprio ou de terceiros)

Fonte: Resultados da pesquisa

Na Figura 5, observa-se que o produtor rural somente será indiferente, entre realizar o investimento com recursos próprios ou de terceiros, quando a taxa de juros real do financiamento for igual à TMA do projeto, que corresponde à 3,7\% a.a. Salientase que a taxa de juros real pode ser calculada através da equação (6), apresentada na seção de materiais e métodos.

\section{Conclusão}

O beneficiamento constitui uma etapa muito importante para a produção de sementes, promovendo vantagens como o aprimoramento do lote, maior facilidade de comercialização e obtenção de um bônus ou prêmio sobre o preço do produto. Quando o produtor rural opta pela atividade, sabe que deverá realizar investimentos em máquinas e implementos, capacitação profissional, infraestrutura de benfeitorias e maiores dispêndios com as operações de campo. Diante dos resultados observados, é possível concluir que o investimento visando a instalação de uma UBS, no caso do produtor analisado, possui viabilidade financeira. O investimento trará benefícios 
econômicos ao empreendimento como um todo, agregando valor ao produto final e elevando, por conseguinte, a rentabilidade da atividade.

A análise também revelou que as condições do financiamento bancário, que possui uma taxa de juros real negativa, elevam significativamente o resultado proporcionado pelo projeto, com o VPL passando de $\mathrm{R} \$ 11.082 .279,19$ (em caso de investimento com recursos próprios) para $\mathrm{R} \$ 14.716 .511,27$. Verificou-se, portanto, que o crédito subsidiado possui uma participação de $24,7 \%$ na composição do valor agregado pela UBS. Outra vantagem, associada a opção de financiamento, deve-se ao fato de que o produtor não imobilizará recursos próprios, que futuramente poderão ser aplicados em outras necessidades da atividade.

Outros trabalhos, que considerem situações ou fatores não contemplados neste estudo, podem corroborar com os resultados encontrados, oferecendo novas contribuições ao encaminhamento do assunto. Um primeiro exemplo seria o de um trabalho que verificasse a viabilidade de investimento em uma UBS para produtores rurais que, além de beneficiarem a semente, também participam da fase de comercialização do produto, pagando royalties às empresas sementeiras; outra sugestão seria a de trabalhos que estudassem o uso de mitigadores de riscos intrínsecos à atividade, ou o uso de contratos entre as partes envolvidas no processo produtivo, entre outros.

\section{Referências}

Bacha, C.J.C. 2014. Tributação no Agronegócio: análise de seus impactos sobre preços, folha de pagamento e lucros. 2. ed. Campinas: Alínea. 116 p.

Barros, A.S.R.; Marcos Filho, J. 1997. Testes para avaliação rápida da viabilidade de sementes de soja. Revista Brasileira de Sementes, v. 19: 289-295.

Buarque, C. 1991. Avaliação econômica de projetos: uma apresentação didática. Rio de Janeiro: Campus, 266p.

Carvalho, N.M.; Nakagawa, J. 2000. Sementes: Ciência, Tecnologia e Produção. - 4. ed. Jabotical: Funep, 588p.

Contador, C.R. 2008. Projetos sociais: avaliação e prática. São Paulo: Atlas, 375p.

Costa, N.P.; Pereira, L.A.G.; França Neto, J.B.; Henning, A.A.; Krzyzanowski, F.C. 1994. Zoneamento ecológico do Estado do Paraná para produção de sementes de cultivares precoces de soja. Revista Brasileira de Sementes. Brasília, v.16, n.1: 12-19.

Dajoz, R. 1981. Ecologia Geral. Petrópolis: Vozes, 47p. 
França Neto, J.B.; Krzyzanowski, F.C. 2000. Produção de sementes de soja: fatores de campo. Seed News. Pelotas, n.4, 20-23.

França Neto, J.B.; Krzyzanowski, F.C.; Pádua, G.P.; Costa, N.P.; Henning, A.A. 2007. Tecnologia da produção de semente de soja de alta qualidade - Série Sementes. Londrina: Embrapa Soja, 12p. (Circular Técnica, 40). Disponível em: http: www.infoteca.cnptia.embrapa.br/bitstream/doc/467586/1/circtec40.pdf. Acesso em: 03 jun. 2014.

Ross, S.A.; Westerfield, R.W.; Jaffe, J.F. 2007. Administração financeira: corporate finance. São Paulo: Atlas, 776p.

Ross, S.A.; Westerfield, R.W.; Jordan, B.D. 2002. Princípios de Administração Financeira. São Paulo: Atlas, 523p.

Thal, L.S. 1982. Sensitivity analysis - a way to make feasibility analysis work. Appraisal Journal, 50: 57-62.

Mankiw, N.G. 2000. Macroeconomics. New York: Worth Publishers, 553 p. 
ANEXO A - Cenário A - Produtor sem UBS (R\$)

(continua)

\begin{tabular}{|c|c|c|c|c|c|c|c|c|c|c|c|}
\hline Anos & Ano 0 & Ano 1 & Ano 2 & Ano 3 & Ano 4 & Ano 5 & Ano 6 & Ano 7 & Ano 8 & Ano 9 & Ano 10 \\
\hline \multicolumn{12}{|l|}{ Receita com sementes } \\
\hline Soja - Brasília (DF) & & 7.336 .003 & 7.336 .003 & 7.336 .003 & 7.336 .003 & 7.336 .003 & 7.336 .003 & 7.336 .003 & 7.336 .003 & 7.336 .003 & 7.336 .003 \\
\hline Soja - Mimoso de Goiás (GO) & & 6.184 .215 & 6.184 .215 & 6.184 .215 & 6.184 .215 & 6.184 .215 & 6.184 .215 & 6.184 .215 & 6.184 .215 & 6.184 .215 & 6.184 .215 \\
\hline Soja - Unaí (MG) & & 2.690 .007 & 2.690 .007 & 2.690 .007 & 2.690 .007 & 2.690 .007 & 2.690.007 & 2.690 .007 & 2.690 .007 & 2.690 .007 & 2.690 .007 \\
\hline \multicolumn{12}{|l|}{ Receita com soja convencional } \\
\hline Soja - Brasília (DF) & & 3.623 .996 & 3.623 .996 & 3.623.996 & 3.623 .996 & 3.623 .996 & 3.623.996 & 3.623 .996 & 3.623.996 & 3.623 .996 & 3.623.996 \\
\hline Soja - Mimoso de Goiás (GO) & & 3.055 .011 & 3.055 .011 & 3.055.011 & 3.055 .011 & 3.055 .011 & 3.055.011 & 3.055 .011 & 3.055 .011 & 3.055 .011 & 3.055.011 \\
\hline Soja - Unaí (MG) & & 1.328 .867 & 1.328 .867 & 1.328 .867 & 1.328 .867 & 1.328 .867 & 1.328 .867 & 1.328 .867 & 1.328 .867 & 1.328 .867 & 1.328 .867 \\
\hline $\begin{array}{l}\text { RECEITA TOTAL } \\
\text { Despesas }\end{array}$ & & 24.218 .100 & 24.218 .100 & 24.218 .100 & 24.218 .100 & 24.218 .100 & 24.218 .100 & 24.218 .100 & 24.218 .100 & 24.218 .100 & 24.218 .100 \\
\hline Custo - Brasília (DF) & & -4.894 .850 & -4.894 .850 & -4.894 .850 & -4.894 .850 & -4.894 .850 & -4.894 .850 & -4.894 .850 & -4.894 .850 & -4.894 .850 & -4.894 .850 \\
\hline Custo - Mimoso de Goiás (GO) & & -4.126 .335 & -4.126 .335 & -4.126 .335 & -4.126 .335 & -4.126 .335 & -4.126 .335 & -4.126 .335 & -4.126 .335 & -4.126 .335 & -4.126 .335 \\
\hline Custo - Unaí (MG) & & -1.739 .543 & -1.739 .543 & -1.739 .543 & -1.739 .543 & -1.739 .543 & -1.739 .543 & -1.739 .543 & -1.739 .543 & -1.739 .543 & -1.739 .543 \\
\hline Imposto de Renda Pessoa Física (IRPF) & & -1.322 .082 & -1.322 .082 & -1.322 .082 & -1.322 .082 & -1.322 .082 & -1.322 .082 & -1.322 .082 & -1.322 .082 & -1.322 .082 & -1.322 .082 \\
\hline FUNRURAL & & -557.016 & -557.016 & -557.016 & -557.016 & -557.016 & -557.016 & -557.016 & -557.016 & -557.016 & -557.016 \\
\hline DESPESA TOTAL & & -12.639 .826 & -12.639 .826 & -12.639 .826 & -12.639 .826 & -12.639 .826 & -12.639 .826 & -12.639 .826 & -12.639 .826 & -12.639 .826 & -12.639 .826 \\
\hline Receita Líquida & & 11.578 .274 & 11.578 .274 & 11.578 .274 & 11.578 .274 & 11.578.274 & 11.578 .274 & 11.578.274 & 11.578 .274 & 11.578 .274 & . 11.578 .274 \\
\hline Fluxo de Caixa Operacional & & 11.578 .274 & 11.578 .274 & 11.578 .274 & 11.578 .274 & 11.578 .274 & 11.578 .274 & 11.578 .274 & 11.578 .274 & 11.578 .274 & 11.578 .274 \\
\hline
\end{tabular}


ANEXO A - Cenário A - Produtor sem UBS (R\$)

(conclusão)

\begin{tabular}{|c|c|c|c|c|c|c|c|c|c|c|}
\hline Anos & Ano 11 & Ano 12 & Ano 13 & Ano 14 & Ano 15 & Ano 16 & Ano 17 & Ano 18 & Ano 19 & Ano 20 \\
\hline \multicolumn{11}{|l|}{ Receita com sementes } \\
\hline Soja - Brasília (DF) & 7.336 .003 & 7.336 .003 & 7.336 .003 & 7.336 .003 & 7.336 .003 & 7.336 .003 & 7.336 .003 & 7.336.003 & 7.336 .003 & 7.336 .003 \\
\hline Soja - Mimoso de Goiás (GO) & 6.184 .215 & 6.184 .215 & 6.184 .215 & 6.184 .215 & 6.184 .215 & 6.184 .215 & 6.184 .215 & 6.184 .215 & 6.184 .215 & 6.184 .215 \\
\hline Soja - Unaí (MG) & 2.690 .007 & 2.690 .007 & 2.690 .007 & 2.690 .007 & 2.690 .007 & 2.690 .007 & 2.690 .007 & 2.690 .007 & 2.690 .007 & 2.690 .007 \\
\hline \multicolumn{11}{|l|}{ Receita com soja convencional } \\
\hline Soja - Brasília (DF) & 3.623 .996 & 3.623 .996 & 3.623 .996 & 3.623 .996 & 3.623 .996 & 3.623 .996 & 3.623 .996 & 3.623 .996 & 3.623 .996 & 3.623 .996 \\
\hline Soja - Mimoso de Goiás (GO) & 3.055 .011 & 3.055 .011 & 3.055 .011 & 3.055 .011 & 3.055 .011 & 3.055 .011 & 3.055 .011 & 3.055 .011 & 3.055 .011 & 3.055 .011 \\
\hline Soja - Unaí (MG) & 1.328 .867 & 1.328 .867 & 1.328 .867 & 1.328 .867 & 1.328 .867 & 1.328 .867 & 1.328 .867 & 1.328 .867 & 1.328 .867 & 1.328 .867 \\
\hline RECEITA TOTAL & 24.218 .100 & 24.218 .100 & 24.218 .100 & 24.218 .100 & 24.218 .100 & 24.218 .100 & 24.218 .100 & 24.218 .100 & 24.218 .100 & 24.218 .100 \\
\hline \multicolumn{11}{|c|}{ 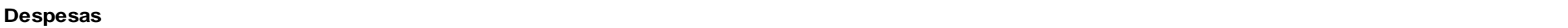 } \\
\hline Custo - Brasília (DF) & -4.894 .850 & -4.894 .850 & -4.894 .850 & -4.894 .850 & -4.894 .850 & -4.894 .850 & -4.894 .850 & -4.894 .850 & -4.894 .850 & -4.894 .850 \\
\hline Custo - Mimoso de Goiás (GO) & -4.126 .335 & -4.126 .335 & -4.126 .335 & -4.126 .335 & -4.126 .335 & -4.126 .335 & -4.126 .335 & -4.126 .335 & -4.126 .335 & -4.126 .335 \\
\hline Custo - Unaí (MG) & -1.739 .543 & -1.739 .543 & -1.739 .543 & -1.739 .543 & -1.739 .543 & -1.739 .543 & -1.739 .543 & -1.739 .543 & -1.739 .543 & -1.739 .543 \\
\hline Imposto de Renda Pessoa Física (IRPF) & -1.322 .082 & -1.322 .082 & -1.322 .082 & -1.322 .082 & -1.322 .082 & -1.322 .082 & -1.322 .082 & -1.322 .082 & -1.322 .082 & -1.322 .082 \\
\hline FUNRURAL & -557.016 & -557.016 & -557.016 & -557.016 & -557.016 & -557.016 & -557.016 & -557.016 & -557.016 & -557.016 \\
\hline DESPESA TOTAL & -12.639 .826 & -12.639 .826 & -12.639 .826 & -12.639 .826 & -12.639 .826 & -12.639 .826 & -12.639 .826 & -12.639 .826 & -12.639 .826 & -12.639 .826 \\
\hline Receita Líquida & 11.578 .274 & 11.578 .274 & 11.578 .274 & 11.578 .274 & 11.578 .274 & 11.578 .274 & 11.578 .274 & 11.578 .274 & 11.578 .274 & 11.578 .274 \\
\hline $\begin{array}{l}\text { Fluxo de Caixa Operacional } \\
\text { Valor Presente Líquido (VPL) }\end{array}$ & 11.578 .274 & 11.578 .274 & 11.578 .274 & 11.578 .274 & 11.578 .274 & 11.578 .274 & 11.578 .274 & 11.578 .274 & 11.578 .274 & 11.578 .274 \\
\hline
\end{tabular}


ANEXO B - Cenário B - Produtor com UBS (R\$)

(continua)

\section{Anos \\ Receita com sementes}

Soja - Brasília (DF)

Soja - Mimoso de Goiás (GO)

Soja - Unaí (MG)

Receita com soja convenciona

Soja - Brasília (DF)

Soja - Mimoso de Goiás (GO)

Soja - Unaí (MG)

Valor residual

\section{RECEITATOTAL}

\section{Despesas}

Custo - Brasília (DF)

Custo - Mimoso de Goiás (GO)

Custo - Unaí (MG)

ICMS - Soja - Mimoso de Goiás (GO)

ICMS - Soja - Unaí (MG)

Custo Operacional da UBS

ICMS - Semente - Mimoso de Goiás (GO)

ICMS - Semente - Unaí (MG)

Frete - Mimoso de Goiás (GO)

Frete - Unaí (MG)

ICMS - Frete

Imposto de Renda Pessoa Física (IRPF)

FUNRURAL

\section{DESPESA TOTAL}

Receita Líquida

Investimento

Fluxo de Caixa Operaciona

Valor Presente Líquido (VPL)
Ano 0

Ano 1

Ano 2

Ano 3

Ano 4

Ano 5

$\begin{array}{llllllllll}9.422 .389 & 9.422 .389 & 9.422 .389 & 9.422 .389 & 9.422 .389 & 9.422 .389 & 9.422 .389 & 9.422 .389 & 9.422 .389 & 9.422 .389 \\ 8.540 .891 & 8.540 .891 & 8.540 .891 & 8.540 .891 & 8.540 .891 & 8.540 .891 & 8.540 .891 & 8.540 .891 & 8.540 .891 & 8.540 .891 \\ 3.544 .138 & 3.544 .138 & 3.544 .138 & 3.544 .138 & 3.544 .138 & 3.544 .138 & 3.544 .138 & 3.544 .138 & 3.544 .138 & 3.544 .138 \\ & & & & & & & & & \\ 3.623 .996 & 3.623 .996 & 3.623 .996 & 3.623 .996 & 3.623 .996 & 3.623 .996 & 3.623 .996 & 3.623 .996 & 3.623 .996 & 3.623 .996 \\ 3.055 .011 & 3.055 .011 & 3.055 .011 & 3.055 .011 & 3.055 .011 & 3.055 .011 & 3.055 .011 & 3.055 .011 & 3.055 .011 & 3.055 .011 \\ 1.328 .867 & 1.328 .867 & 1.328 .867 & 1.328 .867 & 1.328 .867 & 1.328 .867 & 1.328 .867 & 1.328 .867 & 1.328 .867 & 1.328 .867\end{array}$

$\begin{array}{lllllllllll}1.328 .867 & 1.328 .867 & 1.328 .867 & 1.328 .867 & 1.328 .867 & 1.328 .867 & 1.328 .867 & 1.328 .867 & 1.328 .867 & 1.328 .867\end{array}$

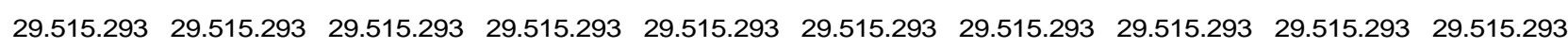

$\begin{array}{lllllllllll}-4.894 .850 & -4.894 .850 & -4.894 .850 & -4.894 .850 & -4.894 .850 & -4.894 .850 & -4.894 .850 & -4.894 .850 & -4.894 .850 & -4.894 .850\end{array}$

$\begin{array}{lllllllllll}-4.126 .335 & -4.126 .335 & -4.126 .335 & -4.126 .335 & -4.126 .335 & -4.126 .335 & -4.126 .335 & -4.126 .335 & -4.126 .335 & -4.126 .335\end{array}$

$\begin{array}{llllllllll}-1.739 .543 & -1.739 .543 & -1.739 .543 & -1.739 .543 & -1.739 .543 & -1.739 .543 & -1.739 .543 & -1.739 .543 & -1.739 .543 & -1.739 .543\end{array}$

$\begin{array}{lllllllllll}-397.151 & -397.151 & -397.151 & -397.151 & -397.151 & -397.151 & -397.151 & -397.151 & -397.151 & -397.151\end{array}$

$\begin{array}{llllllllll}-172.753 & -172.753 & -172.753 & -172.753 & -172.753 & -172.753 & -172.753 & -172.753 & -172.753 & -172.753\end{array}$

$\begin{array}{llllllllll}-2.251 .170 & -2.251 .170 & -2.251 .170 & -2.251 .170 & -2.251 .170 & -2.251 .170 & -2.251 .170 & -2.251 .170 & -2.251 .170 & -2.251 .170\end{array}$

$\begin{array}{lllllllllll}-200.711 & -200.711 & -200.711 & -200.711 & -200.711 & -200.711 & -200.711 & -200.711 & -200.711 & -200.711\end{array}$

$\begin{array}{llllllllll}-75.337 & -75.337 & -75.337 & -75.337 & -75.337 & -75.337 & -75.337 & -75.337 & -75.337 & -75.337\end{array}$

$\begin{array}{llllllllll}-222.313 & -222.313 & -222.313 & -222.313 & -222.313 & -222.313 & -222.313 & -222.313 & -222.313 & -222.313\end{array}$

$\begin{array}{llllllllll}-79.073 & -79.073 & -79.073 & -79.073 & -79.073 & -79.073 & -79.073 & -79.073 & -79.073 & -79.073 \\ - & -21.097 & -21.097 & -21.097 & -21.097 & -21.097 & -21.097 & -21.097 & -21.097 & -21.097\end{array}$

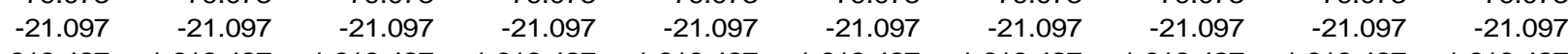

$\begin{array}{llllllllll}-1.613 .427 & -1.613 .427 & -1.613 .427 & -1.613 .427 & -1.613 .427 & -1.613 .427 & -1.613 .427 & -1.613 .427 & -1.613 .427 & -1.613 .427\end{array}$ $\begin{array}{llllllllll}-678.852 & -678.852 & -678.852 & -678.852 & -678.852 & -678.852 & -678.852 & -678.852 & -678.852 & -678.852\end{array}$

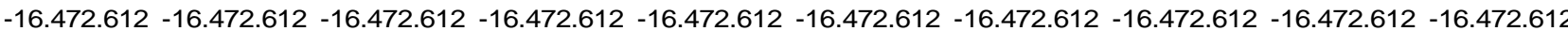
$\begin{array}{llllllllll}13.042 .681 & 13.042 .681 & 13.042 .681 & 13.042 .681 & 13.042 .681 & 13.042 .681 & 13.042 .681 & 13.042 .681 & 13.042 .681 & 13.042 .681\end{array}$

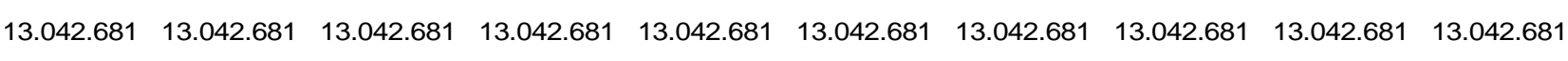


ANEXO B - Cenário B - Produtor com UBS (R\$)

(conclusão)

\begin{tabular}{|c|c|c|c|c|c|c|c|c|c|c|}
\hline Anos & Ano 11 & Ano 12 & Ano 13 & Ano 14 & Ano 15 & Ano 16 & Ano 17 & Ano 18 & Ano 19 & Ano 20 \\
\hline \multicolumn{11}{|l|}{ Receita com sementes } \\
\hline Soja - Brasília (DF) & 9.422 .389 & 9.422 .389 & 9.422 .389 & 9.422 .389 & 9.422 .389 & 9.422 .389 & 9.422 .389 & 9.422 .389 & 9.422 .389 & 7.336 .003 \\
\hline Soja - Mimoso de Goiás (GO) & 8.540 .891 & 8.540 .891 & 8.540 .891 & 8.540 .891 & 8.540 .891 & 8.540 .891 & 8.540 .891 & 8.540 .891 & 8.540 .891 & 6.184 .215 \\
\hline Soja - Unaí (MG) & 3.544 .138 & 3.544 .138 & 3.544 .138 & 3.544 .138 & 3.544 .138 & 3.544 .138 & 3.544 .138 & 3.544 .138 & 3.544 .138 & 2.690 .007 \\
\hline \multicolumn{11}{|l|}{ Receita com soja convencional } \\
\hline Soja - Brasília (DF) & 3.623 .996 & 3.623 .996 & 3.623 .996 & 3.623 .996 & 3.623 .996 & 3.623.996 & 3.623.996 & 3.623 .996 & 3.623 .996 & 3.623.996 \\
\hline Soja - Mimoso de Goiás (GO) & 3.055 .011 & 3.055 .011 & 3.055 .011 & 3.055 .011 & 3.055 .011 & 3.055 .011 & 3.055 .011 & 3.055 .011 & 3.055 .011 & 3.055.011 \\
\hline Soja - Unaí (MG) & 1.328 .867 & 1.328 .867 & 1.328 .867 & 1.328 .867 & 1.328 .867 & 1.328 .867 & 1.328 .867 & 1.328 .867 & 1.328 .867 & 1.328 .867 \\
\hline Valor residual & & & & & & & & & & 1.901 .922 \\
\hline $\begin{array}{l}\text { RECEITA TOTAL } \\
\text { Despesas }\end{array}$ & 29.515 .293 & 29.515 .293 & 29.515 .293 & 29.515 .293 & 29.515 .293 & 29.515 .293 & 29.515 .293 & 29.515 .293 & 29.515 .293 & 26.120 .023 \\
\hline Custo - Brasília (DF) & -4.894 .850 & -4.894 .850 & -4.894 .850 & -4.894 .850 & -4.894 .850 & -4.894 .850 & -4.894 .850 & -4.894 .850 & -4.894 .850 & -4.894 .850 \\
\hline Custo - Mimoso de Goiás (GO) & -4.126 .335 & -4.126 .335 & -4.126 .335 & -4.126 .335 & -4.126 .335 & -4.126 .335 & -4.126 .335 & -4.126 .335 & -4.126 .335 & -4.126 .335 \\
\hline Custo - Unaí (MG) & -1.739 .543 & -1.739 .543 & -1.739 .543 & -1.739 .543 & -1.739 .543 & -1.739 .543 & -1.739 .543 & -1.739 .543 & -1.739 .543 & -1.739 .543 \\
\hline ICMS - Soja - Mimoso de Goiás (GO) & -397.151 & -397.151 & -397.151 & -397.151 & -397.151 & -397.151 & -397.151 & -397.151 & -397.151 & 0 \\
\hline ICMS - Soja - Unaí (MG) & -172.753 & -172.753 & -172.753 & -172.753 & -172.753 & -172.753 & -172.753 & -172.753 & -172.753 & 0 \\
\hline Custo Operacional da UBS & -2.251 .170 & -2.251 .170 & -2.251 .170 & -2.251 .170 & -2.251 .170 & -2.251 .170 & -2.251 .170 & -2.251 .170 & -2.251 .170 & 0 \\
\hline ICMS - Semente - Mimoso de Goiás (GO) & -200.711 & -200.711 & -200.711 & -200.711 & -200.711 & -200.711 & -200.711 & -200.711 & -200.711 & 0 \\
\hline ICMS - Semente - Unaí (MG) & -75.337 & -75.337 & -75.337 & -75.337 & -75.337 & -75.337 & -75.337 & -75.337 & -75.337 & 0 \\
\hline Frete - Mimoso de Goiás (GO) & -222.313 & -222.313 & -222.313 & -222.313 & -222.313 & -222.313 & -222.313 & -222.313 & -222.313 & 0 \\
\hline Frete - Unaí (MG) & -79.073 & -79.073 & -79.073 & -79.073 & -79.073 & -79.073 & -79.073 & -79.073 & -79.073 & 0 \\
\hline ICMS - Frete & -21.097 & -21.097 & -21.097 & -21.097 & -21.097 & -21.097 & -21.097 & -21.097 & -21.097 & 0 \\
\hline Imposto de Renda Pessoa Física (IRPF) & -1.613 .427 & -1.613 .427 & -1.613 .427 & -1.613 .427 & -1.613 .427 & -1.613 .427 & -1.613 .427 & -1.613 .427 & -1.613 .427 & -1.426 .687 \\
\hline FUNRURAL & -678.852 & -678.852 & -678.852 & -678.852 & -678.852 & -678.852 & -678.852 & -678.852 & -678.852 & -600.761 \\
\hline DESPESA TOTAL & -16.472 .612 & -16.472 .612 & -16.472 .612 & -16.472 .612 & -16.472 .612 & -16.472 .612 & -16.472 .612 & -16.472 .612 & -16.472 .612 & -12.788 .176 \\
\hline $\begin{array}{l}\text { Receita Líquida } \\
\text { Investimento }\end{array}$ & 13.042 .681 & 13.042 .681 & 13.042.681 & 13.042 .681 & 13.042 .681 & 13.042 .681 & 13.042 .681 & 13.042 .681 & 13.042 .681 & 13.331 .846 \\
\hline $\begin{array}{l}\text { Fluxo de Caixa Operacional } \\
\text { Valor Presente Líquido (VPL) }\end{array}$ & 13.042 .681 & 13.042 .681 & 13.042 .681 & 13.042 .681 & 13.042 .681 & 13.042 .681 & 13.042 .681 & 13.042.681 & 13.042.681 & 13.331 .846 \\
\hline
\end{tabular}


ANEXO C - Fluxo de caixa incremental (R\$)

(continua)

\begin{tabular}{|c|c|c|c|c|c|c|c|c|c|c|c|}
\hline Anos & Ano 0 & Ano 1 & Ano 2 & Ano 3 & Ano 4 & Ano 5 & Ano 6 & Ano 7 & Ano 8 & Ano 9 & Ano 10 \\
\hline Investimento & -9.509 .611 & 0 & 0 & 0 & 0 & 0 & 0 & 0 & 0 & 0 & 0 \\
\hline Receita Líquida Incremental & 0 & 1.464 .407 & 1.464 .407 & 1.464 .407 & 1.464 .407 & 1.464 .407 & 1.464 .407 & 1.464 .407 & 1.464 .407 & 1.464 .407 & 1.464 .407 \\
\hline $\begin{array}{l}\text { Fluxo de caixa incremental } \\
\text { Valor Presente Líquido (VPL) }\end{array}$ & $\begin{array}{r}-9.509 .611 \\
11.082 .279\end{array}$ & 1.464 .407 & 1.464 .407 & 1.464 .407 & 1.464 .407 & 1.464 .407 & 1.464 .407 & 1.464 .407 & 1.464 .407 & 1.464 .407 & 1.464 .407 \\
\hline
\end{tabular}

(conclusão)

\begin{tabular}{lccccccccccc}
\hline Anos & Ano 11 & Ano 12 & Ano 13 & Ano 14 & Ano 15 & Ano 16 & Ano 17 & Ano 18 & Ano 19 & Ano 20 \\
\hline Investimento & 0 & 0 & 0 & 0 & 0 & 0 & 0 & 0 & 0 & 0 & 0 \\
Receita Líquida Incremental & 1.464 .407 & 1.464 .407 & 1.464 .407 & 1.464 .407 & 1.464 .407 & 1.464 .407 & 1.464 .407 & 1.464 .407 & 1.464 .407 & 1.753 .572 \\
Fluxo de caixa incremental & 1.464 .407 & 1.464 .407 & 1.464 .407 & 1.464 .407 & 1.464 .407 & 1.464 .407 & 1.464 .407 & 1.464 .407 & 1.464 .407 & 1.753 .572 \\
Valor Presente Líquido (VPL) & & & & & & & & & & & \\
\hline
\end{tabular}

\section{ANEXO D - Fluxo do financiamento $(\mathbf{R} \$)$}

(continua)

\begin{tabular}{|c|c|c|c|c|c|c|c|c|c|c|c|}
\hline Anos & Ano 0 & Ano 1 & Ano 2 & Ano 3 & Ano 4 & Ano 5 & Ano 6 & Ano 7 & Ano 8 & Ano 9 & Ano 10 \\
\hline Empréstimo & 9.509 .611 & 0 & 0 & 0 & 0 & 0 & 0 & 0 & 0 & 0 & 0 \\
\hline Pagamento & 0 & 0 & 0 & 0 & -742.954 & -731.067 & -719.370 & -707.860 & -696.534 & -685.389 & -674.423 \\
\hline Fluxo do financiamento & 9.509 .611 & 0 & 0 & 0 & -742.954 & -731.067 & -719.370 & -707.860 & -696.534 & -685.389 & -674.423 \\
\hline Valor Presente Líquido (VPL) & 3.634.232 & & & & & & & & & & \\
\hline
\end{tabular}

(conclusão)

\begin{tabular}{|c|c|c|c|c|c|c|c|c|c|c|}
\hline Anos & Ano 11 & Ano 12 & Ano 13 & Ano 14 & Ano 15 & Ano 16 & Ano 17 & Ano 18 & Ano 19 & Ano 20 \\
\hline Empréstimo & 0 & 0 & 0 & 0 & 0 & 0 & 0 & 0 & 0 & 0 \\
\hline Pagamento & -663.632 & -653.014 & -642.566 & -632.285 & -622.168 & 0 & 0 & 0 & 0 & 0 \\
\hline $\begin{array}{l}\text { Fluxo do financiamento } \\
\text { Valor Presente Líquido (VPL) }\end{array}$ & -663.632 & -653.014 & -642.566 & -632.285 & -622.168 & 0 & 0 & 0 & 0 & 0 \\
\hline
\end{tabular}

